\title{
Article \\ Strength Characteristics of Iron Tailings Blended Soil as a Road Base Material
}

\author{
Jiannan Tong ${ }^{1, *}$, Xujing Niu ${ }^{2}$, Yonghua Wang ${ }^{1}$ and Yunhua $\mathrm{Lu}^{1}$ \\ 1 School of Civil Engineering, Tangshan University, Tangshan 063000, China; tscwyh@sina.com (Y.W.); \\ ts-luhuahua@163.com (Y.L.) \\ 2 State Key Laboratory of Hydroscience and Engineering, Tsinghua University, Beijing 100084, China; \\ wonderfulnxj@tsinghua.edu.cn \\ * Correspondence: tongiiannan126@sina.com
}

\section{check for}

updates

Citation: Tong, J.; Niu, X.; Wang, Y.; Lu, Y. Strength Characteristics of Iron Tailings Blended Soil as a Road Base Material. Appl. Sci. 2021, 11, 7587. https://doi.org/10.3390/app11167587

Academic Editor: Yuzo Nakamura

Received: 23 May 2021

Accepted: 14 August 2021

Published: 18 August 2021

Publisher's Note: MDPI stays neutral with regard to jurisdictional claims in published maps and institutional affiliations.

Copyright: (c) 2021 by the authors. Licensee MDPI, Basel, Switzerland. This article is an open access article distributed under the terms and conditions of the Creative Commons Attribution (CC BY) license (https:/ / creativecommons.org/licenses/by/ $4.0 /)$.

\begin{abstract}
Cement and ionic curing agent were blended with iron tailings (ITS) and natural soil to prepare a new road base material. 7-d unconfined compressive strength (UCS) was selected as the evaluation index for determining the optimal mix ratio. The results reveal that the 7-d UCS always increases with the increase of cement content, and firstly increases with the increase of curing agent content and then tends to remain stable, exhibiting an increasing trend first and then dropping with the increase of ITS content. In lieu of this, the optimum ratio of iron tailings blended soil (ITBS) is determined as follows: ITS and soil are mixed in ratio of 50:50, and cement and soil curing agent account for $5 \%$ and $2 \%$ of the total mass, respectively. The results of splitting strength and flexural-tensile strength tests show that these strengths of the ITBS always increase with the curing age, and firstly increases and then decreases with the increase in ITS content. XRD and SEM analyses show that the ratio of ITS to soil significantly influences the micro-pore structure of the blended soil. At an ITS to soil ratio of 50\%:50\%, the combination of soil and ITS particles is the closest which results in the highest strength attainment.
\end{abstract}

Keywords: iron tailings; road base material; strength characteristics; microstructure

\section{Introduction}

With the rapid development of Chinese society particularly across China, the process of road transportation is also constantly advancing and cutting-edge technologies are being applied. The highway construction system has improved to a large extent, however, the shortage of the raw materials such as sand and gravel and the escalating prices increase project costa [1], thus resulting in a series of constraints. As an important part of its mineral resources, iron ore mining in China discharges nearly 300 million tons of iron tailings (ITS) annually, such that a large amount of these can only be piled up in the form of tailings ponds. Presently, the utilization rate of ITS resources in China is only about 50\% [2,3]. The elevated levels of the tailing ponds are largely attributed to the increase of ITS discharge. The tailings accumulation exhibits fluidity which tends to collapse and thus poses a serious threat to the environment [4-7]. Therefore, the rational utilization of ITS resources is of immense significance.

According to various researchers, ITS have good application prospects in road engineering [8-12]. Manjunatha and Sunil [13] studied the stabilization and solidification of ITS using lime and fly ash with the partial addition of Portland cement by means of the unconfined compressive strength (UCS), hydraulic conductivity, and leaching propensity tests. Osinubi et al. [14] studied the effect of ITS on cement modified tropical black clay, and found the optimal blend is $4 \%$ cement and $6 \%$ tailings. Bastos et al. [15] investigated iron ore tailings stabilized with cement and slag and concluded that the UCS of $5 \%$ cement mixture complied with strength requirements necessary for the base course of roads. In another study, Ojuri et al. [16] found that mixing laterite with iron ore tailings 
and stabilizing with cement-lime can be used as base material in construction of expressways. Ghanizadeh et al. [17] found that $12 \%$ of the Portland cement and $10-40 \%$ of tailing passes the freezing and thawing criteria for stabilization of low plasticity clay soils. Barati et al. [12] demonstrated that cement-stabilized iron ore tailings may be incorporated in road construction.

In this study, ITS in eastern China were mixed in the soil and the blended soils was stabilized by incorporating soil curing agent and cement. The mechanical properties and durability of the iron tailings blended soil (ITBS) were explored by conducting a multitude of laboratory tests as well as various microstructural tests. Also, the mechanism of ITBS with different materials was analyzed in detail and the performance of the ITBS was comprehensively evaluated in order to promote the application of the newly proposed base material in highways construction.

\section{Materials and Methods}

\subsection{Materials}

Iron tailings were obtained from an iron mine area situated in Anhui Province (China), and their chemical composition is shown in Table 1. The amount of $\mathrm{SiO}_{2}$ in the ITS accounts for $70.82 \%$, while $\mathrm{Fe}_{2} \mathrm{O}_{3}$ and $\mathrm{Al}_{2} \mathrm{O}_{3}$ account for $13.66 \%$ and $5.08 \%$, respectively. This is well in the limits of ASTM to be used as pozzolanic materials as the combined content of silica, alumina and iron oxide is above $70 \%$. The fineness modulus of the ITS is 1.56 whereas the specific gravity is 3.14 .

Table 1. Chemical composition of ITS sand (\%).

\begin{tabular}{ccccccccc}
\hline $\mathrm{SiO}_{2}$ & $\mathrm{Fe}_{2} \mathrm{O}_{3}$ & $\mathrm{Al}_{2} \mathrm{O}_{3}$ & $\mathrm{MgO}$ & $\mathrm{CaO}$ & $\mathbf{K}_{2} \mathrm{O}$ & $\mathrm{Na}_{2} \mathrm{O}$ & $\mathbf{P}_{2} \mathrm{O}_{5}$ & Others \\
\hline 70.82 & 13.66 & 5.08 & 4.55 & 3.48 & 0.92 & 0.64 & 0.31 & 0.54 \\
\hline
\end{tabular}

The organic matter content present in the original soil samples is not detected. These samples were obtained from the excavation site of Ma'anshan Highway from a depth of $2 \sim 3 \mathrm{~m}$ below the ground surface. The collected soil samples were pulverized and dried prior to using. The physical properties of soil are shown in Table 2. The grading curves of soil and ITS are also shown in Figure 1.

Table 2. Physical properties of soil.

\begin{tabular}{ccccc}
\hline Liquid Limit & Plastic Limit & Plastic Index $I_{\mathbf{p}}$ & $\begin{array}{c}\text { Optimum Water } \\
\text { Content }\end{array}$ & Dry Density \\
\hline $39.6 \%$ & $20.8 \%$ & 18.8 & $14.5 \%$ & $1.83 \mathrm{~g} / \mathrm{cm}^{3}$ \\
\hline
\end{tabular}

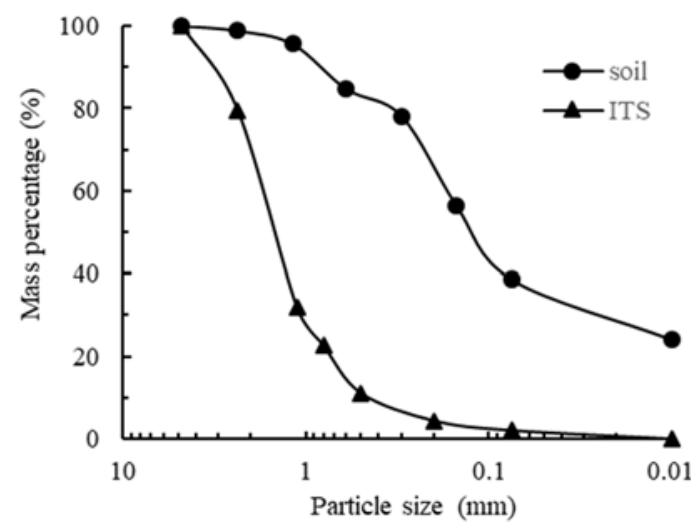

Figure 1. Grain size accumulation curve of tested soil and ITS. 
The cement used for testing purpose is ordinary Portland cement produced by Ma'anshan Conch Cement Co. Ltd. (Ma'anshan, China). The addition of an ionic curing agent ensures that the modified soil exhibits superior water stability, the physical and chemical properties of ionic curing agent is shown in Table 3 [18].

Table 3. Physical and chemical properties of ionic curing agent.

\begin{tabular}{ll}
\hline Parameter & Value or Description \\
\hline Component & A by-product of the citrus industry \\
Color & Black, dark amber \\
State & Liquid \\
Density & $1.70 \mathrm{~g} / \mathrm{cm}^{3}$ \\
Solubility & Completely soluble in water \\
Odor & Sharp sulfurous smell \\
\hline
\end{tabular}

\subsection{Test Methods}

According to the guidelines of test method given in test regulations for inorganic binder stabilized materials in highway engineering (JTGE51-2019) [19], the native soil, tailings, soil curing agent, water and cement were accurately weighed in accordance with the specified ratio of each testing material in Table 4. Firstly, the ITS and soil were mixed and stirred and the soil curing agent was added to the weighed water for dilution such that $80 \%$ diluted solution was sprayed into the modified soil to ensure uniform stirring. After that, it was placed inside a sealed bag to cure for $12 \mathrm{~h}$ duration. Then, the required cement and the remaining $20 \%$ dilute solution were added into the modified soil to ensure secondary stirring. Finally, the ITBS is statically pressed into a cylindrical sample having a diameter and height of $50 \mathrm{~mm}$ by using a jack and a mould and was then put into a standard curing box. Unconfined compressive strength (UCS) tests were conducted when the particular age was reached.

Table 4. Mixture ratios of experimental materials 1 .

\begin{tabular}{cccc}
\hline ITS Content (\%) & Cement Content (\%) & Curing Agent (\%) & Water Content (\%) \\
\hline $30,40,50,60,70$ & $0,1,2,3,4,5$ & $0,0.5,1,1.5,2$ & $8,10,12,14,16$ \\
\hline
\end{tabular}

${ }^{1}$ The contents given here are the percentages of the corresponding substances in the ITS and the plain soil.

Splitting tensile strength refers to the ultimate strength of the tested materials under axial tension. The preparation and curing of samples for this test are consistent with those of UCS samples. The tests in this study were conducted using a pavement material strength testing machine. Firstly, the splitting test fixture was installed in the equipment, and the cylindrical specimen was placed horizontally between the upper and lower jaws. After that, the loading rate was maintained at $1 \mathrm{~mm} / \mathrm{min}$ to apply pressure to the specimen while recording the pressure value at the time of failure of the ITBS specimen.

The flexural-tensile strength of base material refers to the ultimate strength of bearing axial tension under transverse bending. The sample is uniformly mixed in accordance with the procedure mentioned above. The mould size of flexural strength is $50 \mathrm{~mm} \times 50 \mathrm{~mm} \times 200 \mathrm{~mm}$, the inner wall of the beam mould is brushed with oil and then the mixture is placed into the mould in three layers such that each layer is compacted evenly. After that, the material present in the mould is compressed with the help of jack and counter-force frame, and is then carefully cured in a curing tank. The flexural tensile strength test was carried out on the pavement material strength testing machine by threepoint loading method. The loading rate is kept constant and continuous during the test, and maintaining a loading rate of $50 \mathrm{~mm} / \mathrm{min}$ until failure.

The mineral composition was tested by performing XRD analysis. The diffraction pattern was measured by a D-8 ADVANCE- $X$ X-ray diffractometer (Bruker, Karlsruhe, Germany) such that the scanning range of $2 \theta$ was recorded as $10^{\circ} \sim 80^{\circ}$. Before the XRD 
tests, the tested samples were ground into powder with a size lower than $0.075 \mathrm{~mm}$ and dried at $60^{\circ} \mathrm{C}$ for $12 \mathrm{~h}$.

SEM tests were conducted to investigate the microstructure of ITBS using a JSM6490LV scanning electron microscope of Electronics Co., Ltd. (Tokyo, Japan). The tested samples were immersed in ethanol for $24 \mathrm{~h}$. A small square slice $(5 \mathrm{~mm} \times 5 \mathrm{~mm})$ at the center of sample was taken and then dried at $60^{\circ} \mathrm{C}$ for $12 \mathrm{~h}$. The slice also was vacuum gold-plated as required before scanning.

\section{Results and Discussion}

3.1. Unconfined Compressive Strength

3.1.1. Influence of Iron Tailing Sand Content

Figure 2 shows the variation of UCS of ITBS with 5\% cement and 2\% curing agent after $7 \mathrm{~d}$ depending on the content of ITS. It can be seen from the figure that, at higher contents of ITS, the strength is firstly observed to increase and then decreases afterward. It is noteworthy that the strength is recorded to be the highest when the ratio of tailing sand to soil (ITS: soil) is 50:50. This can be attributed to the fact that when the content of ITS is less and the content of soil is more, the material strength is mainly derived from the stacking of internal particles and the friction between the surfaces, whereas the effective cohesion between the particles is less. The activity of ITS increases with the increase of ITS. The generated C-S-H gel material is combined with aggregates of soil particles which can increase the cohesion by efficaciously binding the individual particles and achieve the purpose of filling material internal clearance. However, with the increase of tailings content, the gap formed by tailings sand is not filled with sufficient amount of clay and as a result the strength is decreased.

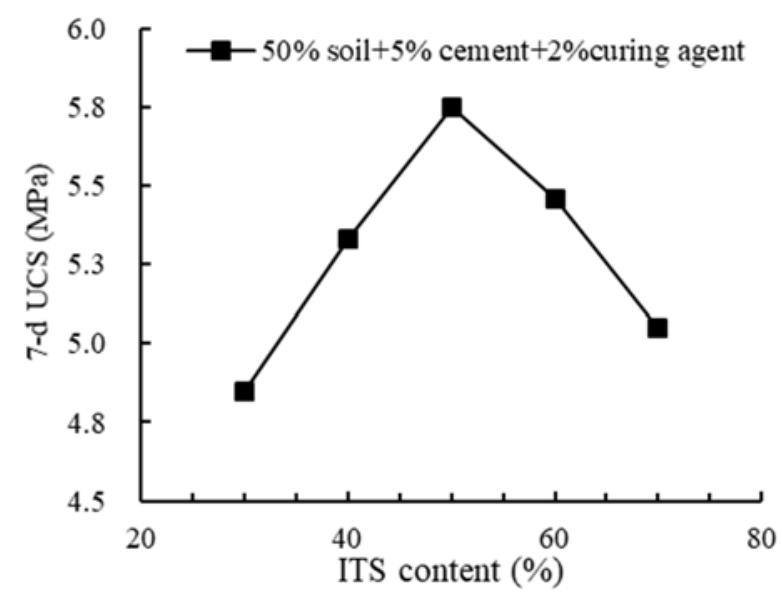

Figure 2. 7-d UCS of ITBS at different ITS contents.

\subsubsection{Influence of Cement Content}

Figure 3 shows the effect of cement content on 7-d UCS of the ITBS with ITS: soil $=50 \%: 50 \%$ and $2 \%$ curing agent. It can be seen that the cement content is directly related to the strength gain. The main reason associated to this is the production of calcium silicate hydrate (C-S-H) gel by the hydration reaction of cement and water, which increases with an increase in the cement content. Therefore, when the cement content is relatively small, only a few hydration products are formed that are not effectively inter connected. The C-S-H gel only reacts with the soil particles that leads to the cementation, solidification and ion exchange processes. With the increase of cement content, the hydrated products also increase, and at this time these products are not only cemented with the soil particles, but they also tend to react with each other and may also overlap thereby connecting the soil particles more closely and hence the soil strength is improved. 


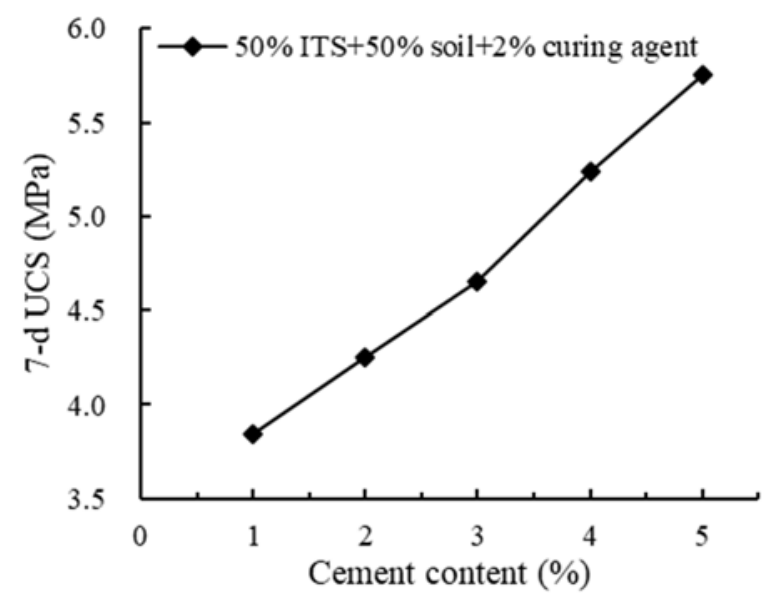

Figure 3. 7-d UCS of ITBS at different cement contents.

\subsubsection{Influence of Soil Curing Agent Content}

An ITBS with ITS:soil $=50 \%: 50 \%$ and 5\% cement was selected to analyze the effect of soil curing agent content on 7-d UCS, as shown in Figure 4. It can be seen that the UCS of the mixture increases with the increase of curing agent content. This is attributed to the mechanism of soil curing agent that solidifies the ITBS and is mainly composed of the ion exchange and alkali-activated cementitious activity of tailings [20]. When the concentration of soil curing agent increases, the concentration of active high valence ions increases, and therefore the ion exchange reaction finally yields solidification effect for tailings mixed soil. However, it can also be seen that when the content of curing agent is more than $2 \%$, the increase of UCS is no longer obvious. The UCS of ITBS with $2 \%$ curing agent is $5.75 \mathrm{MPa}$ and increases to $5.99 \mathrm{MPa}$ for ITBS with $3 \%$ curing agent, only increases by $4 \%$.

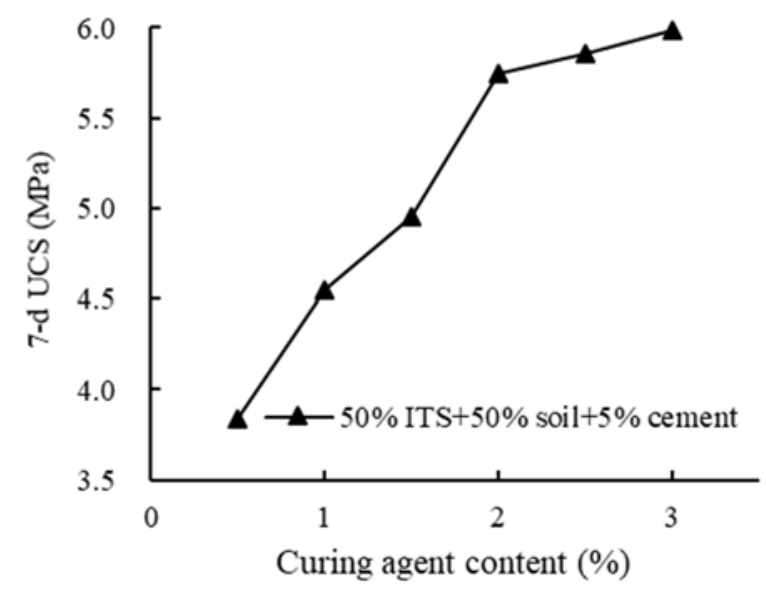

Figure 4. 7-d UCS of ITBS at different curing agent contents.

According to the 7-d UCS, the optimal mix proportion is ITS:soil $=50 \%: 50 \%$, and then mixed with $5 \%$ cement and $2 \%$ soil curing agent in total weight of ITS and soil, such that the 7-d UCS can reach about $5.75 \mathrm{MPa}$, which meets the requirements of most road pavement bases (JTGE51-2019).

\subsubsection{Influence of Water Content}

For the mixture prepared using the optimal mix proportion, the influence of moisture content on the compressive strength is analyzed and has been depicted in Figure 5. It can be seen that the 7-d UCS first increases and then decreases with the increase of water content. When the moisture content is $12 \%$, the strength reaches the peak value of $5.75 \mathrm{MPa}$ whereas when the moisture content is between $10 \%$ and $14 \%$, the strength can be maintained in the 
range of $5.0 \pm 0.5 \mathrm{MPa}$, so in the actual construction process, the moisture content should be controlled at around $12 \pm 2 \%$, which is beneficial to control the in-situ water content near the optimum water content, and can ameliorate the performance of the material.

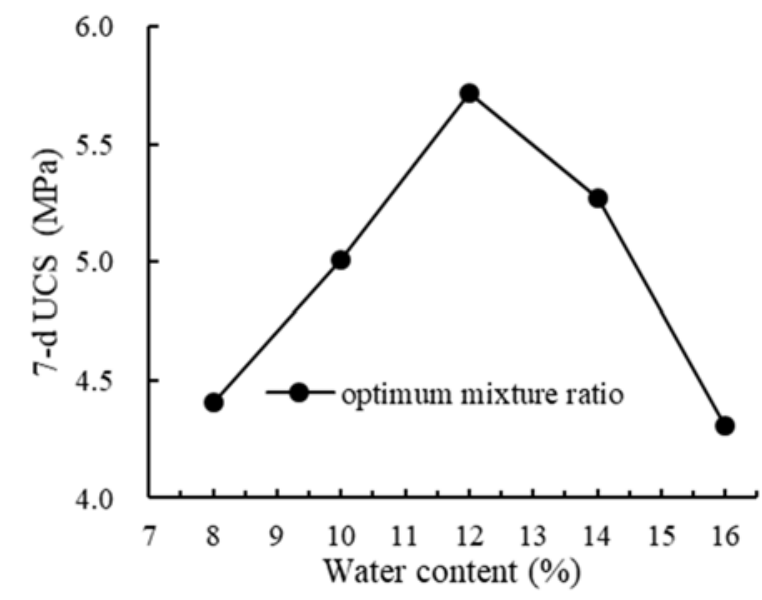

Figure 5. 7-d UCS of ITBS at different water contents.

\subsubsection{Water Stability}

The UCS of ITBS samples at different ages of standard curing and soaking curing were measured, as shown in Figure 6. The ITBS samples were made with the optimal mix ratio. Soaking curing is to soak to the required age after 3 days of normal curing. The test results show that the compressive strength of the mixture gradually increases with the age, and the growth rate increases rapidly within 28 days followed by a gradual drop down afterwards. The results further reveal that with the increase of age, the physical and chemical reactions between the ITBS and the curing agent and cement are gradually stimulated. Simultaneously, it can be observed that the strength of soaking curing samples is lower than those of standard curing samples. At the curing age of 7, 14, 28, 60 and $90 \mathrm{~d}$, the strength of soaking curing samples is reported as $86.36 \%, 82.27 \%, 78.40 \%, 75.54 \%$ and $75.63 \%$ of the standard curing samples, respectively. Therefore, it can be inferred that ITBS can still maintain a certain compressive strength under long-term soaking conditions, and the comprehensive water stability is better under the action of soil curing agent.

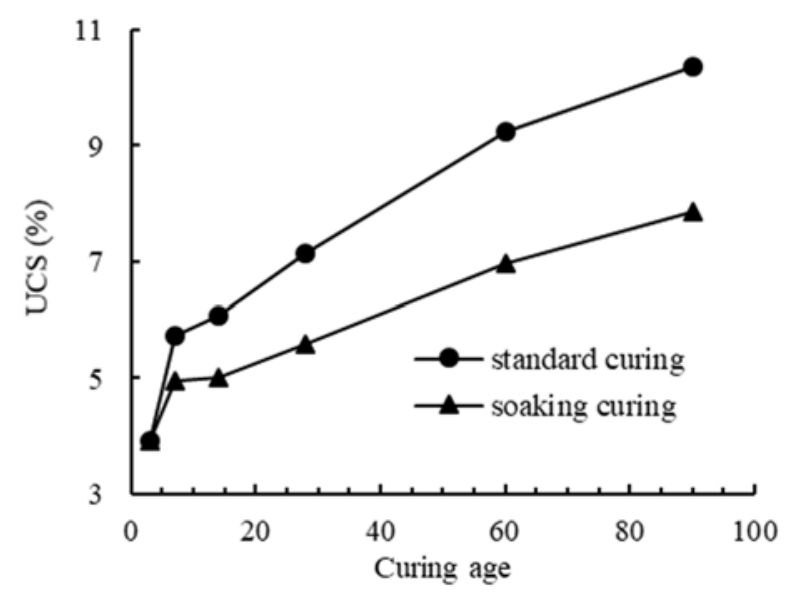

Figure 6. UCS of ITBS under different curing conditions.

\subsection{Splitting Strength and Flexural-Tensile Strength}

Splitting strength tests of different cement content, ITS content and curing ages were performed, and the test results are shown in Figure 7. It can be seen that the splitting strength of the mixture gradually increases with the increase of curing age. When the 
curing age is fixed, the splitting strength of the mixture first increases and then decreases with the increase of ITS content.

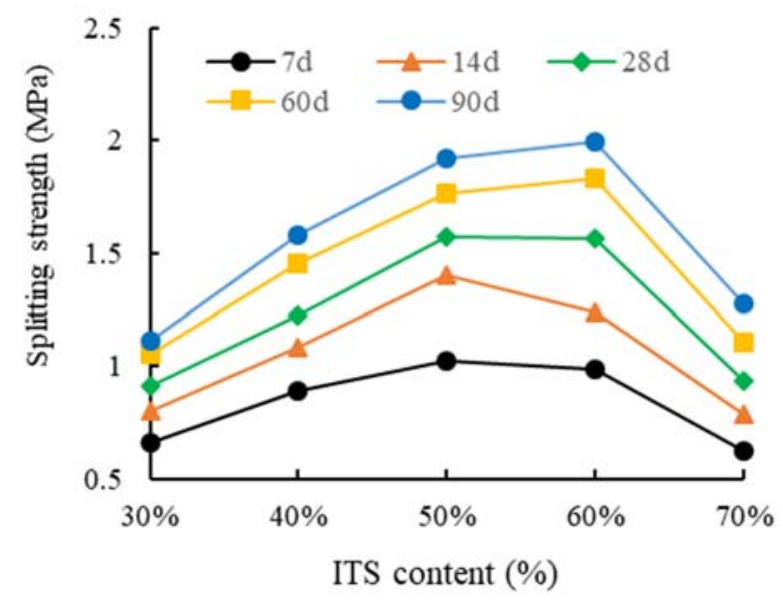

Figure 7. Splitting strength of ITBS with $5 \%$ cement, $2 \%$ curing agent and different ITS content.

Flexural-tensile strength tests of different cement content, ITS content and curing ages were carried out respectively, the test results are shown in Figure 8. It can also be seen that the flexural tensile strength of the mixture gradually increases with the increase of curing age, and first increases and then decreases with the increase of ITS content.

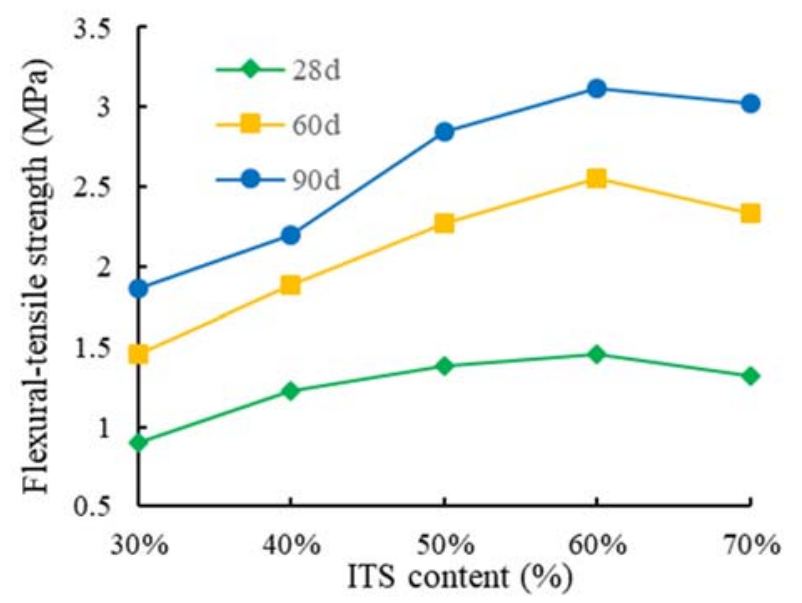

Figure 8. Flexural-tensile strength of ITBS with $5 \%$ cement, $2 \%$ curing agent and different ITS content.

\subsection{Mineral Compositions Affected by Additive Agents}

X-ray diffraction (XRD) analyses were deployed to evaluate the microscopic mechanism of strength behavior during various phase changes. Based on the best mix proportion of ITBS, these samples were prepared as follows: ITBS with 50\% pure ITS, ITBS with 50\% ITS and $2 \%$ curing agent, ITBS with 50\% ITS and 5\% cement, ITBS with 50\% ITS and 5\% cement and $2 \%$ curing agent were labeled as A, B, C and D respectively.

XRD tests were performed after standard curing for 28 days and the results are depicted in Figure 9. It can be seen that the position and number of diffraction peaks of the four types of samples are approximately identical in nature, but the intensity of diffraction peaks is different, which suggests that the mineral composition is similar but the crystallinity is different. The 1st peak is the diffraction peak of silica (quartz), the 2nd peak is that of albite, the $3 \mathrm{rd}$ one represents the peak of calcium carbonate $\left(\mathrm{CaCO}_{3}\right)$, while the 4 th diffraction peak is that of calcium silicate gel. From the comparison of group $\mathrm{A}$ and group $\mathrm{B}, \mathrm{C}, \mathrm{D}$, it can be seen that there is no new diffraction peak when only the curing agent is added, the diffraction peak intensity of quartz $\left(\mathrm{SiO}_{2}\right)$ and albite $\left(\mathrm{Na}\left(\mathrm{AlSi}_{3} \mathrm{O}_{8}\right)\right)$ increases 
to a certain extent, and other diffraction peaks experience no significant changes. The diffraction peaks of newly formed calcium carbonate $\left(\mathrm{CaCO}_{3}\right)$ and calcium silicate hydrate (C-S-H) gels appear when cement is added alone. The diffraction peaks of newly produced calcium carbonate $\left(\mathrm{CaCO}_{3}\right)$ and calcium silicate hydrate $(\mathrm{C}-\mathrm{S}-\mathrm{H})$ gels also appeared when the solidifying agent and cement are mixed together, and the diffraction peak strength is improved to a certain extent compared with that of only addition of cement. Therefore, the following conclusions can be drawn: (i) the properties of the mixed soil of pure iron tailings after reinforcement by curing agent do not change, however, there is ion exchange [21] between the curing agent itself and the soil particle surface, (ii) calcium silicate hydrate (C-S-H gel) was consolidated by cement hydration to impart strength, and it was also accompanied by formation of small amount of $\mathrm{CaCO}_{3}$ crystals, (iii) the agglomerated particles of the curing agent and the filling action of cement hydration product, i.e., C-S-H gel jointly contribute in strength development.

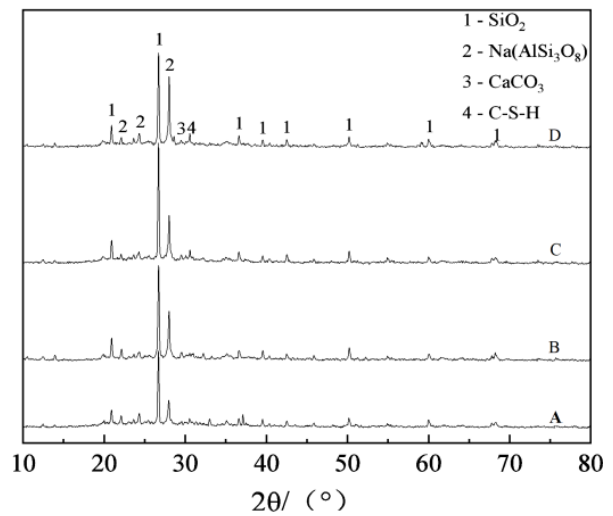

Figure 9. X-ray diffraction spectrum of ITBS. (A) ITBS with 50\% pure ITS; (B) ITBS with $50 \%$ ITS and $2 \%$ curing agent; (C) ITBS with 50\% ITS and 5\% cement; (D) ITBS with 50\% ITS, 5\% cement and 2\% curing agent.

\subsection{Microstructures Affected by Additive Agents}

The above four samples A, B, C, and D were subjected to standardized curing for 7 days, and then SEM images of the samples were taken to reveal the structural differences of ITBS under variety of curing conditions, and the test results are represented in Figure 10.

From Figure 10a, it can be seen that there exist more pores, uniformly distributed particles and better connectivity. The basic unit of soil is mainly granular and flaky and there are irregular aggregates in some of the regions. The basic units are arranged either in point to surface or surface to surface contact mode, stacked to form an overhead loose type of structure, and comprising only a small amount of cementitious materials inside. The appearance of cementitious materials is mainly due to active metal oxides in the native soil as well as the presence of ITS, which can bond the basic units together to an extent and exhibit particular bonding force.

From Figure 10b, it can be seen that the main characteristics of the microstructure include the pores are fine and no longer connected with each other, suggesting that the connection between the basic units is relatively closer. It is noteworthy to mention that the basic units are in the form of surface-to-surface contact. The surface is distributed with viscous material and the pores are also filled with strong bonding and are connected altogether and form some agglomerations. This is because the curing agent can reduce the thickness of the water film on the surface of the particles [20], bring the particles close to each other, form an aggregated structure, increase the density, enhance the overall strength and would finally improve the water stability. 


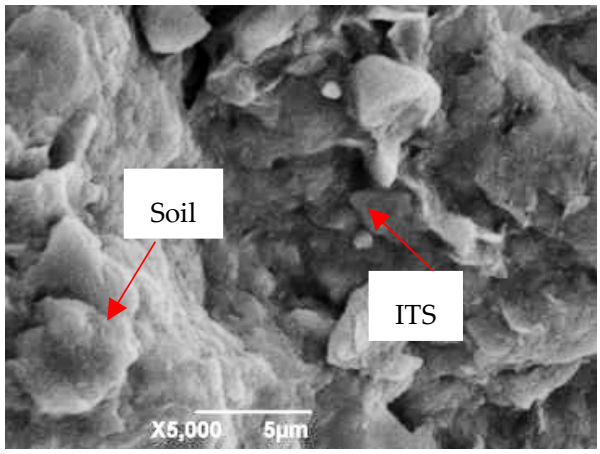

(a)

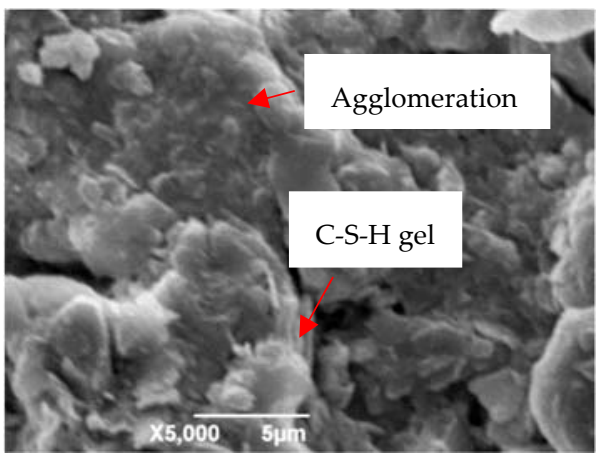

(c)

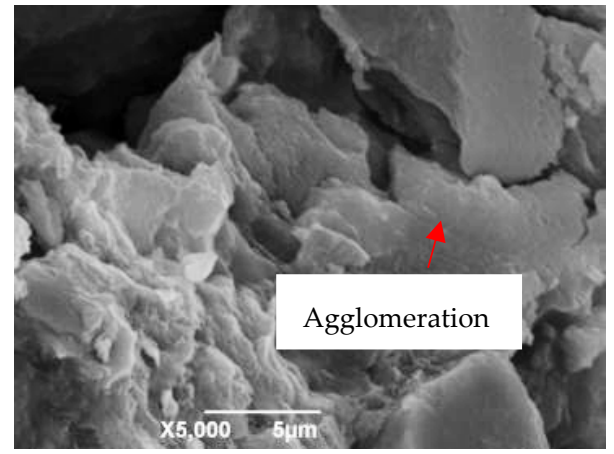

(b)

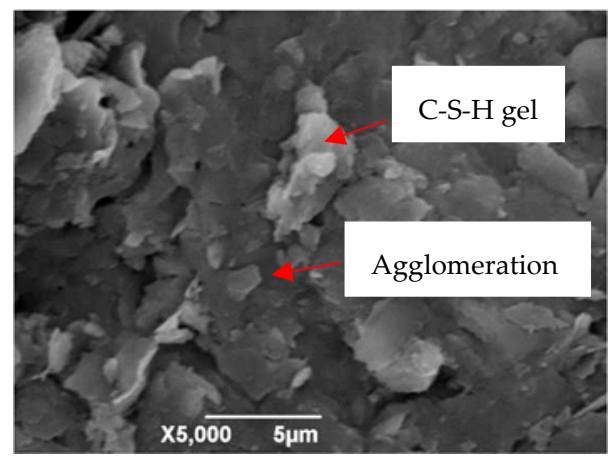

(d)

Figure 10. SEM images of ITBS with (a) 50\% pure ITS; (b) 50\% ITS and 2\% curing agent; (c) ITS and $5 \%$ cement; and (d) ITS and $5 \%$ cement and $2 \%$ curing agent.

From Figure 10c, it can be seen that the main characteristics of the microstructure are a relatively dense appearance as a whole, with large pores and fine cracks. Also, the basic unit is in the form of aggregated structure. The force between the basic units is increased and a large amount of C-S-H gel is filled in it in the form of fiber and flake shape [22,23]. The pozzolanic nature of cement reduces the porosity of the material thereby densifying the structure and thus improving the macroscopic strength, which is consistent with the test results.

From Figure 10d, it can be seen that the main characteristics of the microstructure basically form a whole, without obvious pores, and there exist small cracks which are not interconnected. It is important to mention that the basic unit presents larger aggregates. A large number of flocculated hydration products cover the surface of the basic unit, crisscross, connect the units, fill in the basic unit, reduce the gap between the units, and the density further improve.

This says that the main factors affecting the strength of ITBS are pores, cracks, basic unit types, and hydration products. The addition of curing agent and cement, on the one hand, the basic unit is mainly aggregate type and the volume increases significantly, the space between the units decreases which leads to reduced porosity and hence the compactness increases. On the other hand, hydration process also generates a large amount of C-S-H gel which fill the pores that increases the density and thus enhancing the strength.

\subsection{Microstructures Affected by Iron Tailing Sand Content}

In order to explore the microstructural change of ITBS with different sand and soil ratio, based on the optimal mix proportion of ITBS, adding 5\% cement and $2 \%$ curing agent, ITBS with different proportions of 30\% ITS + 70\% soil, $50 \%$ ITS + 50\% soil, $70 \%$ ITS + 30\% soil were prepared respectively. After standard curing for 28 days, samples were taken for SEM analysis, and the test results are shown in Figure 11. It can be seen from the figure when the ratio of ITS to soil ratio is $30 \%: 70 \%$, the proportion of soil is larger than that of ITS, which represents the wholesomeness of soil particles, so the basic unit is mainly formed by 
the aggregation and stacking of soil particles. The microstructure pores are bigger and have lesser interconnection. The cohesive force between aggregates is also minimal. Therefore, the strength of ITBS with ITS to soil ratio of 30\%:70\% is lower. When the ITS to soil ratio is $50 \%: 50 \%$, the basic unit is formed by the stacking of soil particles and ITS particles, with lesser number of pores on the surface and unconnected micro cracks between them. The cohesive force between aggregates is strong. Therefore, the strength of ITBS with ITS to soil ratio of $50 \%: 50 \%$ is higher. When the ITS to soil ratio is $70 \%: 30 \%$, the proportion of ITS is larger than that of soil and the whole is characterized by "sanding", so the basic unit is mainly composed of ITS particles. Because the pores between sand particles are not filled with a sufficient amount of soil particles, the cracks between the particles are wider and the compactness is reduced, which reduces the strength.

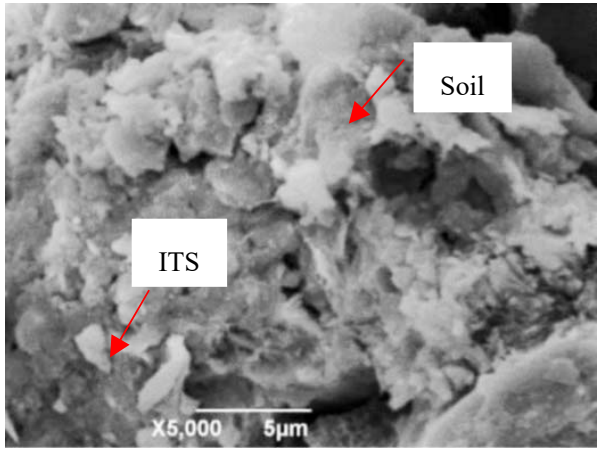

(a)

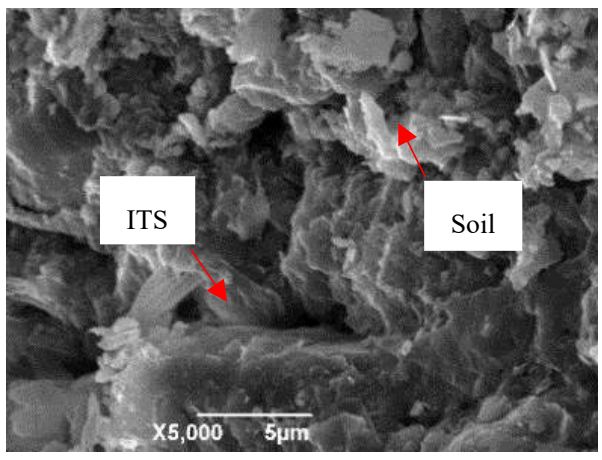

(c)

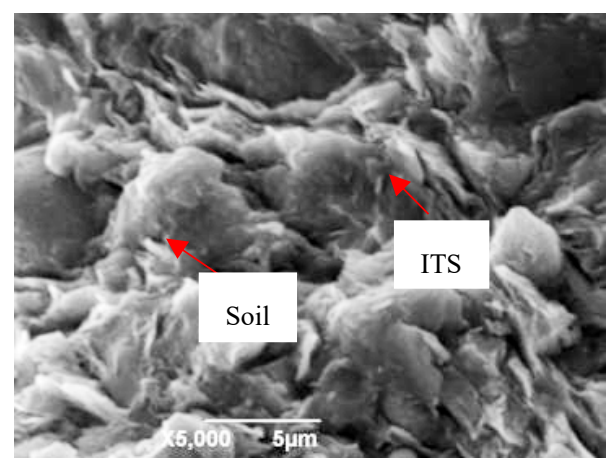

(b)

Figure 11. SEM images of ITBS with (a) ITS:soil = 30:70; (b) ITS:soil = 50:50; and (c) ITS: soil = 70:30.

It can be summarized that due to the difference of particle diameter between ITS and soil, different sand to soil ratio has a significant influence on the pore structure of mixed soil. When one of these two substances has a higher content than the other it will be difficult to ensure the close combination between soil particles and ITS particles. When the contents of the two components are equal, the full connection between sand and soil particles will produce higher strength.

\section{Conclusions}

A new mixture of iron tailings blended with natural soil was designed as a road base material. The optimal mix ratio was assessed, the mechanical properties and mechanism of ITBS with different materials were investigated. The main findings were as follows:

- Considering both economy and practical implications, the optimal mix proportion of ITBS is determined as follows, ITS:soil $=50 \%: 50 \%$, and then mixed with $5 \%$ cement and $2 \%$ soil curing agent in total weight of ITS and soil.

- Under the optimum mix proportion conditions, the compressive strength of ITBS can be effectively exerted when the water content is about $12 \%$. The samples of standard curing and soaking curing increase gradually with the increase of age, and the samples 
under the condition of long-term soaking curing still have high strength assurance rate, and the ITBS has good water stability.

- The splitting strength and flexural tensile strength of the mixture also increase with the increase of age and increase first and then decrease with the increase of the sand to soil ratio.

- The XRD and SEM results show that the addition of curing agent yielded almost no new substances but the ion exchange reaction between curing agent and soil could occur, which made the aggregate more compact. C-S-H gel and $\mathrm{CaCO}_{3}$ were produced in the mixed soil due to hydration of cement. These substances filled the pores of aggregate and made the bond between ITS and soil particles more compact and the strength further increased. Using the curing agent in conjunction with the cement can generate a higher strength. In addition, when the contents of the soil and ITS are equal, the combination between the two components is getting closer.

Author Contributions: Conceptualization, J.T., X.N. and Y.L.; methodology, Y.W.; validation, J.T.; formal analysis, J.T.; investigation, X.N.; data curation, J.T. and X.N.; writing-original draft preparation, Y.W. and Y.L.; writing-review and editing, J.T. and X.N.; visualization, J.T.; supervision, X.N.; project administration, Y.W. All authors have read and agreed to the published version of the manuscript.

Funding: This research received no external funding.

Institutional Review Board Statement: Not applicable.

Informed Consent Statement: Not applicable.

Data Availability Statement: Data is contained within the article.

Conflicts of Interest: The authors declare no conflict of interest.

\section{References}

1. Yu, F.; Cao, Y.; Fang, Y.; Zhang, Y.; Niu, K. Mechanical behavior of self-stressing steel slag aggregate concrete filled steel tubular short columns with different loading modes. Structures 2020, 26, 947-957. [CrossRef]

2. Bing, L.; Zhongying, Z.; Biao, T.; Hongbo, L.; Hanchi, C.; Zhen, M. Comprehensive Utilization of Iron Tailings in China; IOP Publishing: Bristol, UK, 2018; Volume 199.

3. Wang, K.; Liu, Y.; Lyu, G.; Li, X.; Chen, X. A review of comprehensive utilization of high-iron red mud of China. Light Met. 2020, 65-71. [CrossRef]

4. Filho, J.N.S.A.; Da Silva, S.N.; Silva, G.C.; Mendes, J.C.; Peixoto, R.A.F. Technical and environmental feasibility of interlocking concrete pavers with iron ore tailings from tailings dams. J. Mater. Civil Eng. 2017, 29, 04017104. [CrossRef]

5. Lv, X.; Shen, W.; Wang, L.; Dong, Y.; Zhang, J.; Xie, Z. A comparative study on the practical utilization of iron tailings as a complete replacement of normal aggregates in dam concrete with different gradation. J. Clean. Prod. 2019, 211, 704-715. [CrossRef]

6. Flórez, C.; Neumann, R.; Espósito, T.; Barbosa, M.C. Response of granular iron tailings to laboratory-induced environmental stressing. Environ. Geotech. 2020, 40,1-11. [CrossRef]

7. Franks, D.M.; Stringer, M.; Torres-Cruz, L.A.; Baker, E.; Valenta, R.; Thygesen, K.; Barrie, S. Tailings facility disclosures reveal stability risks. Sci. Rep. 2021, 11, 1-7.

8. Xu, S. Research on application of iron tailings on road base. Adv. Mater. Res. 2013, 743, 54-57. [CrossRef]

9. Zhang, X.; Yang, H.; Cui, Z. Evaluation and analysis of soil migration and distribution characteristics of heavy metals in iron tailings. J. Clean. Prod. 2018, 172, 475-480. [CrossRef]

10. Manjarrez, L.; Zhang, L. Utilization of copper mine tailings as road base construction material through geopolymerization. J. Mater. Civil Eng. 2018, 30, 04018201. [CrossRef]

11. Babatunde, A.Q.; Oshioname, E.A.; Paul, Y.; Junwolo, O.K. Effect of elapsed time after mixing on the strength properties of lime-iron ore tailings treated black cotton soil as a road construction material. Infrastructures 2020, 5, 89. [CrossRef]

12. Barati, S.; Tabatabaie Shourijeh, P.; Samani, N.; Asadi, S. Stabilization of iron ore tailings with cement and bentonite: A case study on Golgohar mine. Bull. Eng. Geol. Environ. 2020, 79, 4151-4166. [CrossRef]

13. Manjunatha, L.S.; Sunil, B.M. Stabilization/solidification of iron ore mine tailings using cement, lime and fly ash. Int. J. Res. Eng. 2013, 2, 625-635.

14. Osinubi, K.J.; Yohanna, P.; Eberemu, A.O. Cement modification of tropical black clay using iron ore tailings as admixture. Transp. Geotech. 2015, 5, 35-49. [CrossRef]

15. Bastos, L.A.D.C.; Silva, G.C.; Mendes, J.C.; Peixoto, R.A.F. Using iron ore tailings from tailing dams as road material. J. Mater. Civil Eng. 2016, 28, 04016102. [CrossRef] 
16. Ojuri, O.O.; Adavi, A.A.; Oluwatuyi, O.E. Geotechnical and environmental evaluation of lime-cement stabilized soil-mine tailing mixtures for highway construction. Transp. Geotech. 2017, 10, 1-12. [CrossRef]

17. Ghanizadeh, A.R.; Yarmahmoudi, A.; Abbaslou, H. Mechanical properties of low plasticity clay soil stabilized with iron ore mine tailing and portland cement. J. Min. Env. 2020, 11, 837-853.

18. Wu, X.T.; Sun, J.S.; Qi, Y.; Chen, B. Pore and compression characteristics of clay solidified by ionic soil stabilizer. Bull. Eng. Geol. Environ. 2021, 80, 5003-5019. [CrossRef]

19. Wang, X.D.; Li, M.H.; Sha, A.M.; Wang, S.Y.; Zhou, X.Y.; Shen, G.H.; Lu, K.Y. Test Methods of Materials Stabilized with Inorganic Binders for Highway Engineering, JTG E51-2009; China Communication Press: Beijing, China, 2009.

20. Yao, D.; Qian, G.P.; Yao, J.L.; Liu, J.W.; Yu, X.L. Polymer curing agent in ecological protection design weak rock slope engineering application. J. Perform. Constr. Fac. 2020, 34, 04019115. [CrossRef]

21. Xiang, G.; Ye, W.; Xu, Y.; Jalal, F.E. Swelling deformation of Na-bentonite in solutions containing different cations. Eng. Geol. 2020, 277, 105757. [CrossRef]

22. Bahar, R.; Benazzoug, M.; Kenai, S. Performance of compacted cement-stabilised soil. Cem. Concr. comp. 2004, 26, 811-820. [CrossRef]

23. Sherwood, P. Soil Stabilization with Cement and Lime: State of the Art Review; Her Majesty's Stationery Office: London, UK, 1993. 